\title{
Intensity of EMF generated by electronic safety system devices
}

\author{
Martin Pospisilik ${ }^{1, *}$, Eva Vnencakova $^{2}$, and Milan Kutaj $^{2}$ \\ ${ }^{1}$ Tomas Bata University in Zlin, Faculty of Applied Informatics, Nad Stranemi 4511, 76005 Zlin, Czech Republic \\ ${ }^{2}$ University of Zilina, Faculty of Security Engineering, $1^{\text {st }}$ May Street 32, 01026 Zilina, Slovakia
}

\begin{abstract}
As the importance of wireless networks based on radio frequencies increases in time, a space for discussion on harmfulness of the electromagnetic radiation has occurred. On the one hand there are studies showing that a direct influence of non-ionizing electromagnetic waves on the human organism was not confirmed until a certain intensity has been reached. On the other hand, critical voices appear, warning that even low intensities of non-ionizing electromagnetic fields are harmful to the human body, if it is exposed to the radiation for a prolonged time. The authors of this paper have no ambition to resolve this dispute. However, they provide data on the intensity of the electromagnetic fields generated by several components of electronic security system that are operating on the basis of the wireless network. The data have been gained in a specialized workplace and will allow the reader to imagine how intensive the radio signals generated by the battery-operated devices are compared to the current hygienic and technical limits.
\end{abstract}

\section{Introduction}

Electromagnetic field (EMF) is a physical field produced by electrically charged objects. Its principle and the relevant mechanisms have been studied since 17 th century and the first complete theory to describe this phenomenon was published in 1873 by James Clerk Maxwell. The EMF also include radio waves that have become an object of interest at the turn of the 19th and 20th centuries and currently their importance continues to grow. Physically, the radio waves can be understood as an energy-carrying matter. Its oscillating particles are of a very low weight but they embody great momentum. The energy of the radio waves in quantized. The smallest amount of energy is represented by a photon. The photon's energy is directly proportional to a frequency it oscillates on:

$$
W_{f}=h f[J]
$$

Where $\mathrm{h}=6.625 \cdot 10^{-34}[\mathrm{Js}]$ is a Planck's constant. The relationship between the weight of a photon and its propagation velocity can be expressed by the wellknown Einstein's equation (2). The propagation velocity of EMF is given by the permittivity and the permeability of the ambience (3).

$$
\begin{gathered}
W=m c^{2}[J] \\
c=\frac{1}{\sqrt{\varepsilon_{0} \varepsilon_{r} \mu_{0} \mu_{r}}}[\mathrm{~m} / \mathrm{s}]
\end{gathered}
$$

Where:

$\varepsilon_{0}=8.85 \cdot 10^{-12}[\mathrm{~F} / \mathrm{m}]$ is the vacuum permittivity, $\varepsilon_{r}$ is the permittivity of the ambient material, $\mu_{0}=4 \pi \cdot 10^{-7}\left[N / A^{2}\right]$ is the vacuum permeability, $\mu_{r}$ is the permeability of the ambient material.

As the EMF (radio waves respectively) is the carrier of energy, it has effects on the mass which it interacts. This is useful for information transmissions as the energy of the modulated EMF drives the input of the receiver with no need of wired connection. The direct consequence of this phenomenon is a thermal action on the irradiated matter (microwave ovens) when the EMF intensity is high enough. In a free environment, the EMF intensity is usually expressed in $[\mathrm{V} / \mathrm{m}]$ although the EMF consists of two components, the electrical field and the magnetic field. The intensity of electrical field is expressed in Volts per meter $[\mathrm{V} / \mathrm{m}]$ while the intensity of the magnetic field is expressed in Amperes per meter $[\mathrm{A} / \mathrm{m}]$. However, in the free environment the ratio between the electric and the magnetic fields is fixed. Therefore only one unit $[\mathrm{V} / \mathrm{m}]$ can be used to describe the EMF intensity correctly. The EMF intensity decreases with the distance from its radiator approximately according to the following equation:

$$
E=\frac{\sqrt{30 P}}{r}[V / m]
$$

Where:

$\mathrm{P}$ is the transmitting power of the radiator in Watts, $r$ is the distance from the radiator in metres.

\subsection{Standardization}

Concerning the issues on EMF, thorough technical standardization has been implemented in the past, mostly because of the problems arising from the electromagnetic compatibility of the relevant systems.

* Corresponding author: pospisilik@,fai.utb.cz

C The Authors, published by EDP Sciences. This is an open access article distributed under the terms of the Creative Commons Attribution License 4.0 (http://creativecommons.org/licenses/by/4.0/). 
Generally, the standardization covers two large groups of issues:

- Electromagnetic compatibility of technical systems,

- Electromagnetic compatibility of biological systems.

Although the scientists usually find consensus concerning the technical systems, there are many ambiguous issues on the electromagnetic compatibility of biological systems. Although the effects of EMF on the human organism have been observed for a long time, the results of existing biophysical and biophysical research in this area are not unambiguous. The biological effects of the electromagnetic field depend on its nature, the duration of action, and the properties of the organism. Since field receptors (ie, inputs of the electromagnetic field into the organism) are not known, these effects are only assessed by non-specific reactions of the organism. [1]

In the Czech Republic, the Government Regulation $1 / 2008 \mathrm{Sb}$. defines requirements for work and occurrence of persons in the electromagnetic field in the frequency range $0 \mathrm{~Hz}$ to $300 \mathrm{GHz}$. It also specifies the limits on permissible values of induced currents, absorbed power and irradiance density as enlisted in Table 1.

Table 1. Limits defined by the GR 1/2008 Sb. [7]

\begin{tabular}{|c|c|c|}
\hline Quantity & $\begin{array}{c}\text { Employed } \\
\text { persons }\end{array}$ & $\begin{array}{c}\text { Other } \\
\text { persons }\end{array}$ \\
\hline $\begin{array}{c}\text { Induced current } \\
\text { density }\left[\mathrm{A} / \mathrm{m}^{2}\right]^{1)}\end{array}$ & $\sqrt{2} \cdot 0.01$ & $\sqrt{2} \cdot 002$ \\
\hline $\begin{array}{c}\text { Areal power } \\
\text { density }\left[\mathrm{W} / \mathrm{m}^{2}\right]^{2)}\end{array}$ & 50 & 10 \\
\hline $\begin{array}{c}\text { Specific absorbed } \\
\text { power }[\mathrm{W} / \mathrm{kg}]^{3)}\end{array}$ & $0,4^{4)}$ & $0,08^{5)}$ \\
\hline
\end{tabular}

\footnotetext{
${ }^{1)}$ Valid for frequencies from 300 to $10^{7} \mathrm{~Hz}$.

2) Valid for frequencies from 1 to $3 \mathrm{GHz}$.

${ }^{3)}$ Valid for frequencies from $10^{5}$ to $10^{10} \mathrm{~Hz}$

4) If only a part of a human body is exposed, the limit is increased to $10 \mathrm{~W} / \mathrm{kg}$ or $20 \mathrm{~W} / \mathrm{kg}$ for hands, feet and ankles).

${ }^{5)}$ If only a part of a human body is exposed, the limit is increased to $10 \mathrm{~W} / \mathrm{kg}$ or $20 \mathrm{~W} / \mathrm{kg}$ for hands, feet and ankles).
}

\subsection{Radio Interfaces of Safety Systems}

Usually, the wireless sensors of electronic safety systems employ standardized radio bands 434 and $868 \mathrm{MHz}$. According to the standard EN 300220 [6], the frequency bands of 868.6 to $866.7 \mathrm{MHz}$ is recommended for these purposes. The relevant radio bands and limits suitable for operation of the wireless sensors of electronic safety systems according to [6] are enlisted in the Table 2.

For the purposes of the paper, let us assume that the wireless sensors use antennas that are close to the isotropic ones, i.e. they radiate almost equal amount of power at all directions. Then the appropriate areal power density can be calculated as follows [5]:

$$
S=\mathrm{g} \frac{P_{t}}{4 \pi r^{2}}\left[W / m^{2}\right]
$$

Where:

$\mathrm{g}$ is the antenna gain (1 for isotropic antennas),

$\mathrm{P}_{\mathrm{t}}$ is the transmitted power,

$\mathrm{r}$ is the distance from the transmitter.

Table 2. Suitable radio bands for wireless safety sensors [6]

\begin{tabular}{|c|c|}
\hline Frequency [MHz] & $\begin{array}{c}\text { Effective } \\
\text { radiated power } \\
\text { limit [W] }\end{array}$ \\
\hline $433.05-434.04$ & 0.01 \\
\hline $868.0-868.6$ & 0.025 \\
\hline $868.7-869.2$ & 0.025 \\
\hline
\end{tabular}

When compared to the limits enlisted in Table 1, it can be stated that the transmitting power of these devices is quite negligible.

\section{Tested devices}

For the purposes of the experiment, the below enlisted devices were selected. All of them were provided by the manufacturer as subjects for testing and educational purposes. Primarily, these devices were indented to be tested on their operating ranges and possible vulnerability of their wireless communication. Once they were delivered to the laboratory, the intensity of EMF they transmitted was measured as well.

\subsection{Jablotron JA-160PC}

Jablotron JA-160PC (see Figure 1) is a wireless motion detector with embedded camera. When the alarm is launched, the detector creates a picture of the observed scene. This picture can be transmitted to the control station. The wireless connection is performed in the band of $868 \mathrm{MHz}$. The device is battery operated.

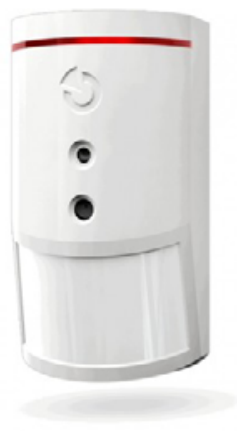

Fig. 1. Jablotron JA-160PC.

\subsection{Jablotron JA-151M}

This is a wireless opening magnetic detector with minimized dimensions. It is a component of JA-100 Alarm system and it is intended to detection of opening 
of window, doors etc. of protected area. The power supply is ensured by a single lithium battery of CR2032 type. It operates in the radio band of $868 \mathrm{MHz}$.

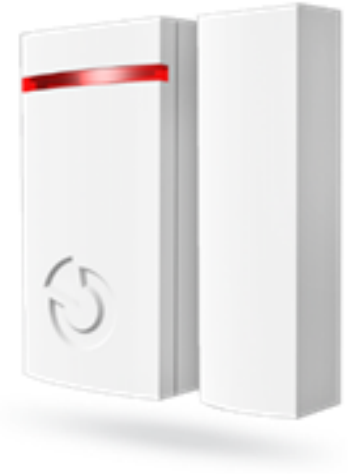

Fig. 2. Jablotron JA-151M.

\subsection{Jablotron JA-180B}

The JA-180B is a component of JA-100 Alarm system and it is intended to detection of glass breaking of glass surfaces of protected area by intruder. Its power supply is provided by an internal battery. It operates at the frequency of $868.1 \mathrm{MHz}$.

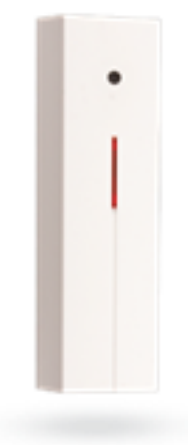

Fig. 3. Jablotron JA-180B.

\section{Experiment description}

The experiment took place in the Laboratory of electromagnetic compatibility at the Faculty of Applied Informatics of Tomas Bata University in Zlin. The measurement was processed inside a semi anechoic chamber Frankonia SAC-3 plus by means of the following equipment:

- $\quad$ EMI test receiver Rohde \& Schwarz ESU 8,

- $\quad$ EMI antenna Teseq CBL 6112.

- Controlling software Rohde \& Schwarz EMC 32.

The construction of the chamber is specific for its cylindrically shaped ceiling. The manufacturer claims that the dome shaped roof as well as its optimized absorber layout, with ferrite and partial hybrid absorber lining, minimizes the reflections in between $26 \mathrm{MHz}$ and $18 \mathrm{GHz}[8]$.

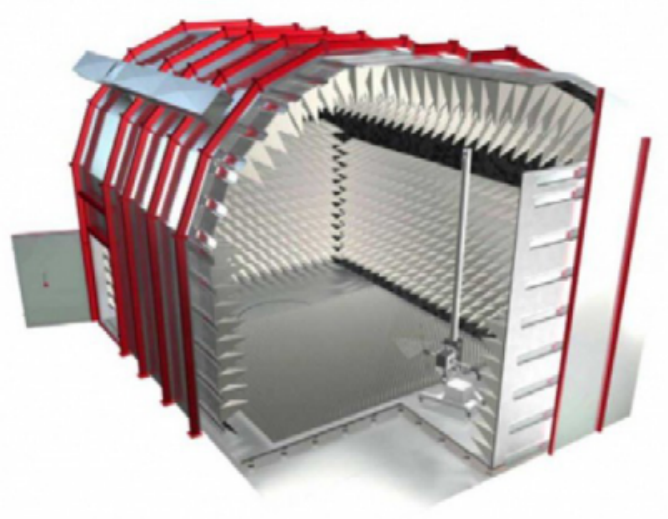

Fig. 4. Frankonia SAC 3 plus.

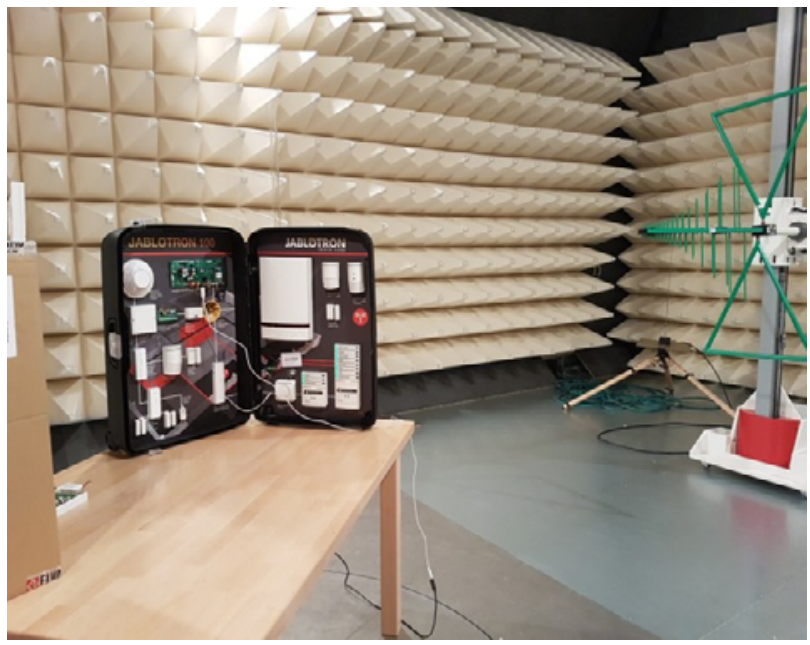

Fig. 5. Safety system Jablotron JA 100 inside the semi anechoic chamber.

\subsection{Configuration}

The configuration of the experiment was as depicted in Figure 5. The tested device was placed at the test table inside the semianechoic chamber and the receiving antenna was placed at an appropriate distance. The test receiver was set to continuously scan the narrow frequency band around the frequency of $868 \mathrm{MHz}$ and to record the maximum measured value (MaxHold). MaxPeak detector was selected for this kind of measurement. During the measurement, the measured device was forced to launch alarm in order to obtain its attempt to establish radio connection between the device and its controlling exchange. Both, the vertical and the horizontal antenna polarization were used. The measurement was processed until no increase of the recorded values was observed. For each of the components, one measurement for vertical and one measurement for horizontal antenna polarization were processed separately. 


\subsection{Interpretation of the results}

Inside the chamber, the intensity of the EMF radiated by the device was measured. Assuming that the manufacturer of the device constructed its transmitting antennas in order to radiate omnidirectionally, the device was treated as the isotropic EMF radiator. The EMF intensity was measured in the distance of 4 metres and transmitting power was calculated according to the equation (5).

\section{Results}

The results obtained by the experiment are enlisted in the Table 3. All the final measurements were processed in the distance of 4 metres.

Table 3. Results obtained by the experiment

\begin{tabular}{|c|c|c|c|c|}
\hline Device & $\begin{array}{c}\text { Radio } \\
\text { Frequency } \\
{[\mathbf{M H z}]}\end{array}$ & $\begin{array}{c}\text { Distance } \\
{[\mathbf{m}]}\end{array}$ & $\begin{array}{c}\text { Measured } \\
\text { Intensity } \\
{[\mathbf{d B} \boldsymbol{\mu} \mathbf{V} / \mathbf{m}]}\end{array}$ & $\begin{array}{c}\text { Transmitting } \\
\text { power }[\mathbf{W}]\end{array}$ \\
\hline JA-160PC & 868.090 & 4 & 101.2 & 0.00707 \\
\hline JA-151M & 868.129 & 4 & 99.7 & 0.00495 \\
\hline JA-180B & 868.089 & 4 & 100.5 & 0.00594 \\
\hline
\end{tabular}

According to [2] and the relevant standards, the irregularity of EVF measurement inside the semi anechoic chamber can be as high as $\pm 4 \mathrm{~dB}$ (relative to the voltage units). Due to the complexity of the problem, this uncertainty is allowed even for officially certified test laboratories. For example, if the measured intensity is $100 \pm 4 \mathrm{~dB} \mu \mathrm{V} / \mathrm{m}$, it means that the real value of EVF may lie somewhere between 63.096 and $158.489 \mathrm{mV} / \mathrm{m}$, resulting in the calculated transmitting power from 2.123 to $13.4 \mathrm{~mW}$. Of course, there are methods to increase the accuracy of the measurement, but they needs a lot of time and expenses in orders of thousands of Euro. Therefore the authors consider the obtained results as satisfying.

Table 4. Power densities calculated from the measured intensities

\begin{tabular}{|c|c|c|c|c|}
\hline \multirow{2}{*}{ Device } & \multirow{2}{*}{$\begin{array}{c}\text { Radio } \\
\text { Frequency } \\
{[\mathrm{MHz}]}\end{array}$} & \multicolumn{2}{|c|}{$\begin{array}{c}\text { Power density } \\
{\left[\mu \mathrm{W} / \mathrm{m}^{2}\right]}\end{array}$} & \multirow{2}{*}{$\begin{array}{c}\text { Transmitting } \\
\text { power [W] }\end{array}$} \\
\hline & & $\begin{array}{c}\text { Distance } \\
\text { of } 1 \mathrm{~m}\end{array}$ & \begin{tabular}{|c|} 
Distance \\
of $4 \mathrm{~m}$
\end{tabular} & \\
\hline JA-160PC & 868.090 & 562.6 & 35.16 & 0.00707 \\
\hline JA-151M & 868.129 & 393.9 & 24.62 & 0.00495 \\
\hline JA-180B & 868.089 & 472.7 & 25.54 & 0.00594 \\
\hline
\end{tabular}

Finally, let us concern the issues on the areal power density as it is expressed in the Table 1. This can be calculated by the equation (5). The calculated power densities in the distance of 1 and 4 metres from the devices are enlisted in the Table 4 . It can surely be stated, that in the distance of $1 \mathrm{~m}$ from the device, even the short-term peak value of the transmitting power is lower than $1 \mathrm{~mW}$. This is $10000 \mathrm{x}$ lower value than required by the Regulation 1/2008 $\mathrm{Sb}$ [7].

\section{Conclusions}

This paper provides description of the experiment that consisted of measurement of the intensity of the electromagnetic field radiated by various wireless sensors of an electronic safety system. During the experiment it was observed that the intensities of radiated EMF of the observed devices were below the limits prescribed by relevant standards [6] and very low when hygienic limits is taken into consideration [7].

In fact, this is not a surprising result. The wireless sensors are battery-operated and therefore they cannot waste the energy pointlessly. To lower the power consumption, the communication between the sensor and the base station is performed periodically with the interval as long as tens of minutes. And, of course, the transmitting power is limited. On the other hand, it turned out that the operating ranges of the devices were shorter than the manufacturer declared.

This work was supported by the Ministry of Education, Youth and Sports of the Czech Republic within the National Sustainability Programme project No. LO1303 (MSMT7778/2014) and also by the European Regional Development Fund under the project CEBIA-Tech No. CZ.1.05/2.1.00/03.0089.

\section{References}

1. J. Svacina, Electromagnetic Compatibility [Elektromagneticka kompatibilita], Brno: VUT Brno, (2002).

2. C. R. Paul, Introduction to Electromagnetic Compatibility, New York: John Wiley, (1992).

3. P. A. Chatterton, M. A. Houlden, EMC Electromagnetic Theory to Practical Design, New York: John Wiley, (1991).

4. M. Mann, B. Gutheil, J. Zastrau, P. Weiss, "Electromagnetic field measurements - Means of verification", In Proc. of the 5th WSEAS/IASME Int. Conf. on Electric Power Systems, High Voltages, Electric Machines, Tenerife, Spain, December 16-18, (2005), pp 591-595.

5. Z. Trnka, Theory of Electrical Engineering [Teoretická elektrotechnika]. Bratislava: SNTL Alfa, (1972).

6. European standard EN 300220.

7. Czech Government Regulation No. 1/2008 Sb.

8. Frankonia: Anechoic Chambers / RF-Shielded Rooms, 2012. 